\title{
Application of ANFIS for Modeling of Microhardness of High Strength Low Alloy (HSLA) Steels in Continuous Cooling
}

\author{
Gholamreza Khalaj ${ }^{\mathrm{a} *}$, Ali Nazari ${ }^{\mathrm{b}}$, Akbar Karimi Livary ${ }^{\mathrm{b}}$ \\ ${ }^{a}$ Department of Materials Engineering, Saveh Branch, Islamic Azad University, Saveh, Iran \\ ${ }^{\mathrm{b}}$ Modeling and Simulation Department, WorldTech Scientific Research Center (WT-SRC), Tehran, Iran
}

Received: July 1, 2012; Revised: November 20, 2012

\begin{abstract}
The paper presents some results of the research connected with the development of new approach based on the Adaptive Network-based Fuzzy Inference Systems (ANFIS) of predicting the Vickers microhardness of the phase constituents occurring in five steel samples after continuous cooling. The independent variables in the model are chemical compositions, initial austenite grain size and cooling rate over the temperature range of the occurrence of phase transformations. To construct these models, 114 different experimental data were gathered from the literature. The data used in the ANFIS model is arranged in a format of twelve input parameters that cover the chemical compositions, initial austenite grain size and cooling rate, and output parameter which is Vickers microhardness. In this model, the training and testing results in the ANFIS systems have shown strong potential for prediction of effects of chemical compositions and heat treatments on hardness of microalloyed steels.
\end{abstract}

Keywords: adaptive network -based fuzzy inference systems (ANFIS), microalloyed steel, continuous cooling, HSLA steel

\section{Introduction}

The addition of alloying elements has been found to overcome the deficiencies of plain carbon steels and has resulted in improved material properties of steel. The thermodynamic stability of phases is changed by the addition of alloying elements to pure iron, which leads to a wide variety of microstructures and mechanical properties obtained as a result of austenite decomposition. For HSLA steels, the base chemistry consists of carbon and manganese where the principle microalloying elements are niobium, vanadium and titanium.

Carbon is an efficient austenite stabilizer and, in general, retards the transformation kinetics by shifting the timetemperature-transformation (TTT) curves to increasingly longer times as the carbon content is increased ${ }^{1}$. As a result, non-equilibrium transformation products such as bainite and martensite can be produced. The driving pressure for austenite decomposition at any temperature is reduced by increasing the carbon content due to a lowering of the Ae3 temperature. In general, low carbon steels are included of carbon contents up to $0.25 \mathrm{wt}$. (\%).

The addition of manganese to low carbon steel produces several important changes. Like carbon, manganese acts as an austenite stabilizer and effectively expands the temperature range where stable austenite can form. The $\mathrm{A}_{\mathrm{e} 3}$ temperature is considerably lowered which can enhance ferrite grain refinement and by increasing the manganese content a transition from a polygonal ferrite-pearlite microstructure to a ferrite-bainite microstructure can be attained ${ }^{2}$.

Niobium and titanium have been found to significantly affect the austenite decomposition kinetics ${ }^{3-5}$. An example

*e-mail: gh.khalaj@ srbiau.ac.ir of the effect of niobium and titanium in solution on the transformation start temperature is shown in Figure 1, which indicates that both niobium and titanium have a strong effect on delaying the start of the proeutectoid ferrite transformation, and that niobium is more effective for this delay than titanium. In addition, niobium and titanium have different affinities for carbon and nitrogen in austenite as shown in Figure 2, so that precipitates of carbides, nitrides and carbonitrides are formed for both niobium and titanium.

Coarse grain boundary precipitates have been found to be potent nucleation sites for ferrite formation due to the large mismatch with austenite which provides a high energy interface suitable for nucleation ${ }^{4}$. In addition, the formation of these coarse precipitates locally reduces the niobium and carbon contents in solution resulting in the effect of solute drag to be decreased and further promoting ferrite nucleation.

Cooling rate is one of the key parameters, which can be adapted on a welding due to its strong effect on the kinetics of austenite decomposition and resulting microstructure ${ }^{6}$. A wide variety of transformation products i.e. polygonal ferrite, acicular ferrite, bainite and/or martensite, can be obtained in HSLA steels by changing the cooling conditions during the continuous cooling phase transformation.

Austenite decomposition is a thermally activated process where the formation of the new product phase requires time to initiate nucleation and to continue into the growth stage. As a result, by increasing the cooling rate the available time at any given temperature to start the nucleation and growth processes is diminished, and thus, shifts the transformation start to lower temperatures ${ }^{6-9}$. Increasing the cooling rate also produces a finer ferrite grain size; since there is a greater difference in free energies of the austenite 


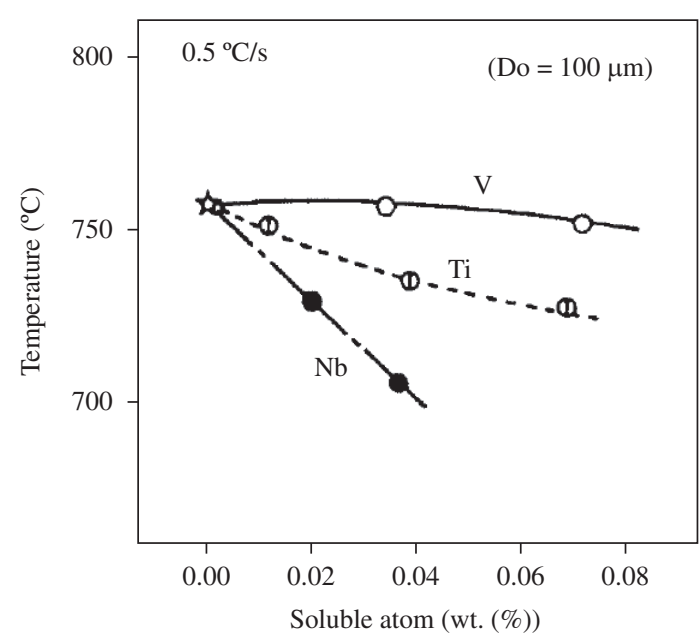

Figure 1. The effect of niobium and titanium in solution on the transformation start temperature $\left(\mathrm{A}_{\mathrm{e} 3}\right)^{3}$.

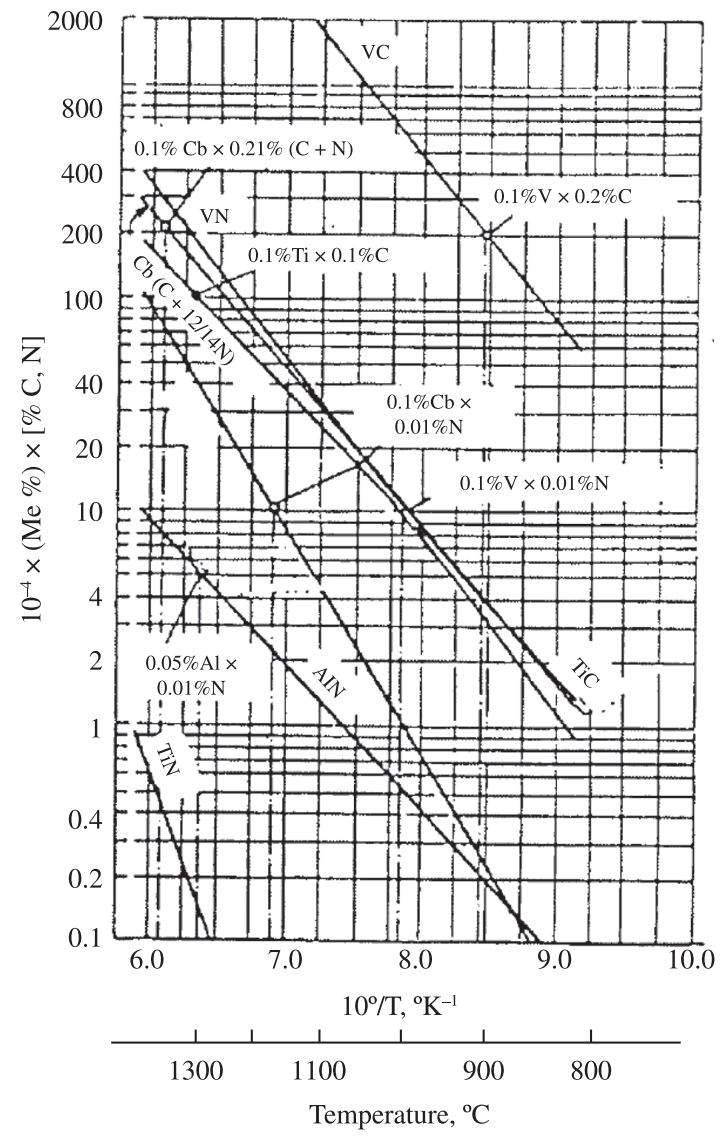

Figure 2. Solubility products of niobium, aluminium, vanadium and titanium nitrides and carbides ${ }^{4}$.

and growing ferrite which leads to the activation of more potential nucleation sites ${ }^{10}$. At very high cooling rates, the transformation rate decreases due to a reduction in the diffusivity of carbon.
In addition to producing a finer ferrite grain size, an increase in the cooling rate can also form low temperature secondary products such as bainite and martensite due to the repression of the transformation start temperature. By controlling the final microstructure through cooling the desired-final mechanical properties of the steel can be achieved. In this way, controlled cooling on the weld heat affected zone (HAZ) is an important thermal treatment which can effectively control the final microstructure and mechanical properties of the steel.

The initial austenite microstructure plays an important role in the transformation behavior for weld HAZ cooling. The two microstructural features of austenite which are important for the transformation process include the austenite grain size and the degree of precipitation.

The heterogeneous nucleation of ferrite occurs prevalently on austenite grain boundaries. Therefore, a decrease of the austenite grain size leads to an increase in the grain boundary area per unit volume and thus a greater surface area for potential nucleation sites. As a result of increasing the number of potential nucleation sites, transformation starts at higher temperatures and produces higher temperature transformation products such as polygonal ferrite ${ }^{6,11}$. A finer ferrite grain size is produced since the number of ferrite formed increases due to more available potential nucleation sites where impingement of the growing ferrite grains will occur earlier due to the decrease of the austenite grain size.

It is observed that with a decrease in the austenite grain size, the transformation rate increases due to the increase in the ratio of nucleation rate to growth rate ${ }^{12-13}$. In addition, formation of polygonal ferrite is depressed with an increase in the austenite grain size and formation of non-polygonal microstructures is promoted ${ }^{6}$.

Several works have addressed utilizing of computeraided prediction of engineering properties including those done by the authors ${ }^{14-19}$. Adaptive Network-based Fuzzy Inference Systems (ANFIS) is the famous hybrid neuro-fuzzy network for modeling the complex systems ${ }^{20}$. ANFIS incorporates the human-like reasoning style of fuzzy systems through the use of fuzzy sets and a linguistic model consisting of a set of IF-THEN fuzzy rules. The main strength of ANFIS models is that they are universal approximators ${ }^{20}$ with the ability to solicit interpretable IFTHEN rules. Nowadays, the artificial intelligence-based techniques like ANFIS ${ }^{21}$ have been successfully applied in the engineering applications. However, there is a lack of investigations on metallurgical aspects of materials.

In the present study, the effects of chemical compositions, austenitizing temperature, austenitic grain size and cooling rate on Vickers microhardness of low-carbon microalloyed steels has been modeled by ANFIS. Totally 114 Vickers microhardness data were collected from the literature, trained, tested and validated by ANFIS. The obtained results were compared by experimental ones to evaluate the software power for predicting the effects of mentioned parameters on microhardness of the studied steels.

\section{Architecture of ANFIS}

The architecture of an ANFIS model with two input variables is shown in Figure 3. Suppose that the rule base 
A, B is of triangular membership function type

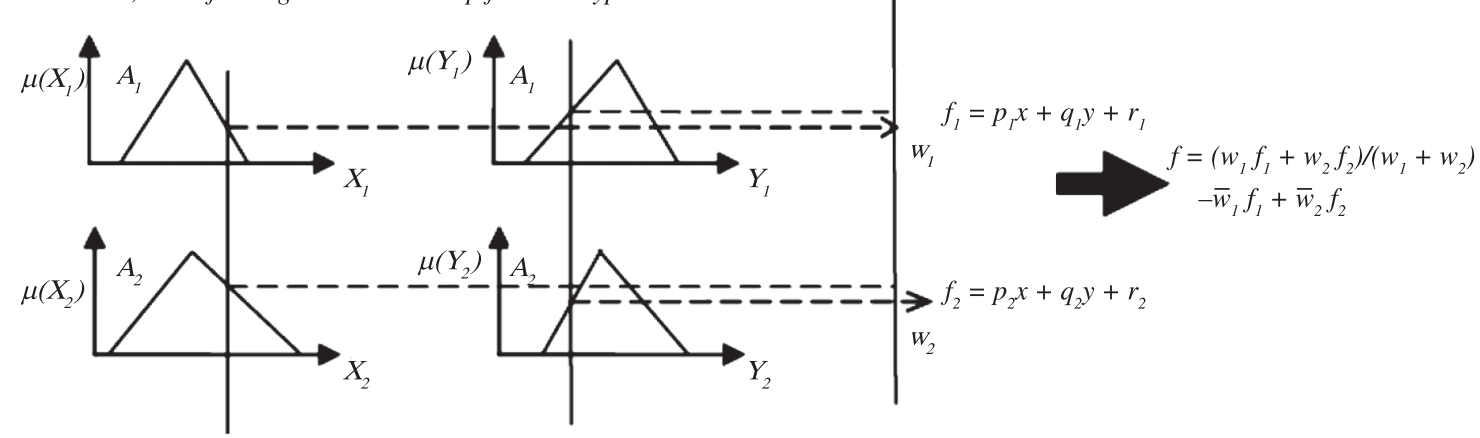

Figure 3. The reasoning sheme of ANFIS ${ }^{22}$.

of ANFIS contains two fuzzy IF-THEN rules of Takagi and Sugeno's type as follows:

Rule 1: IF $\times$ is $A_{1}$ and $y$ is $B_{1}$, THEN $f_{1}=p_{1} x+q_{1} y+r_{1}$.

Rule 2: $I F \times$ is $A_{2}$ and $y$ is $B_{2}$, THEN $f_{2}=p_{2} x+q_{2} y+r_{2}$.

In Figure 3 fuzzy reasoning is illustrated and also the corresponding equivalent ANFIS architecture is shown in Figure 4. The functions of each layer are explained as follows ${ }^{23-27}$ :

Layer 1 - Every node $\mathrm{i}$ in this layer is a square node with a node function:

$O_{i}^{1}=\mu_{A_{i}}(x)$

(fuzzy sets: small, large, ...) associated with this node function.

Layer 2 - Every node in this layer is a circle node labeled $\mathrm{P}$, which multiplies the incoming signals and sends the product out. For instance,

$$
W_{i}=\mu_{A_{i}}(y) \times \mu_{B_{i}}(y) \quad i=1,2
$$

Each node output represents the firing weight of a rule.

Layer 3 -Every node in this layer is a circle node labeled $\mathrm{N}$. The ith node calculates the ratio of the ith rule's firing weight to the sum of all rule's firing weights:

$W_{i}=W_{i} /\left(W_{1} / W_{2}\right), \mathrm{i}=1,2$

Layer 4 - Every node in this layer is a square node with a node function:

$$
O_{i}^{4}=\bar{W}_{i}\left(P_{i} X+q_{i} y+r_{i}\right)
$$

where $\bar{W}_{i}$ is the output of layer 3 , and $\left\{\mathrm{p}_{\mathrm{i}}, \mathrm{q}_{\mathrm{i}}, \mathrm{r}_{\mathrm{i}}\right\}$ is the parameter set.

Layer 5 - The signal node in this layer is a circle node labeled $\mathrm{R}$ that computes the overall output as the summation of all incoming signals, that is,

$O_{i}^{5}=\sum_{i} \bar{W}_{i} f_{i}=\sum_{i} W_{i} f_{i} / \sum_{i} W_{i}$

The basic learning rule of ANFIS is the backpropagation gradient descent, which calculates error signals recursively from the output layer backward to the input nodes. This learning rule is exactly the same as the

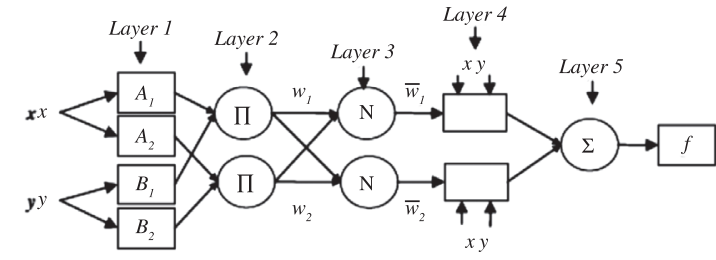

Figure 4. Schematic of ANFIS architecture ${ }^{21}$.

back-propagation learning rule used in the common feedforward neural networks ${ }^{28,29}$. Newly, ANFIS adopted a rapid learning method named as hybrid-learning method that utilizes the gradient descent and the least-squares method to find a feasible set of antecedent and consequent parameters ${ }^{28,29}$. Therefore, in this paper, the later method is used for constructing the proposed models.

\section{Training and Verifying}

\subsection{Data collection}

In the present investigation, the ANFIS has been trained, tested and validated for prediction microhardness of low-carbon microalloyed steels. For this purpose, the experimental data of five low-carbon microalloyed steels with different chemical compositions have been used ${ }^{30-34}$. The chemical compositions of these steels are summarized in Table 1. The input variables of the ANFIS modeling are the weight percent of alloying elements, the initial austenite grain size and the cooling rate. These parameters along with their ranges have been summarized in Table 2 .

\subsection{ANFIS model structure and parameters}

The structure of proposed ANFIS networks consisted of twelve input variables including the carbon concentration $(\mathrm{cC})$, the niobium concentration $(\mathrm{cNb})$, the manganese concentration $(\mathrm{cMn})$, the molybdenum concentration $(\mathrm{cMo})$, the titanium concentration (cTi), the nitrogen concentration $(\mathrm{cN})$, the phosphorous concentration $(\mathrm{cP})$, the sulfur concentration $(\mathrm{cS})$, the silicon concentration $\mathrm{nt}(\mathrm{cSi})$, the aluminum concentration (cAl), the initial austenite grain size $(\mathrm{D} \gamma)$ and the cooling rate (CR). The value for output layer was the Vickers microhardness (HV). 
Table 1. Chemical composition of the microalloyed steels.

\begin{tabular}{llcccccccccc}
\hline \multirow{2}{*}{ Ref. } & \multicolumn{10}{c}{ Steel } & \multicolumn{10}{c}{ Chemical composition (wt. (\%)) } \\
\cline { 3 - 12 } & & $\mathbf{C}$ & $\mathbf{M n}$ & $\mathbf{N b}$ & $\mathbf{M o}$ & $\mathbf{T i}$ & $\mathbf{N}$ & $\mathbf{P}$ & $\mathbf{S}$ & $\mathbf{S i}$ & $\mathbf{A l}$ \\
\hline 26 & X80 & 0.060 & 1.650 & 0.034 & 0.240 & 0.012 & 0.005 & 0.000 & 0.000 & 0.000 & 0.000 \\
27 & HSLA65 & 0.062 & 1.240 & 0.063 & 0.008 & 0.002 & 0.007 & 0.007 & 0.004 & 0.051 & 0.040 \\
27 & HSLA 90 & 0.050 & 1.650 & 0.071 & 0.196 & 0.021 & 0.000 & 0.010 & 0.004 & 0.025 & 0.027 \\
28 & Nb steel & 0.060 & 1.200 & 0.062 & 0.000 & 0.000 & 0.008 & 0.000 & 0.007 & 0.290 & 0.035 \\
29 & Nb-Mo steel & 0.050 & 1.880 & 0.049 & 0.490 & 0.000 & 0.004 & 0.005 & 0.007 & 0.040 & 0.050 \\
30 & DP600 & 0.060 & 1.860 & 0.000 & 0.155 & 0.011 & 0.007 & 0.015 & 0.004 & 0.077 & 0.043 \\
\hline
\end{tabular}

Table 2. The parameters and their range used in the neural network.

\begin{tabular}{cc}
\hline Parameter & Range \\
\hline Input & $0.050-0.062$ \\
$\mathrm{C}($ wt. $(\%))$ & $1.200-1.880$ \\
$\mathrm{Mn}($ wt. $(\%))$ & $0.000-0.071$ \\
$\mathrm{Nb}($ wt. $(\%))$ & $0.008-0.490$ \\
$\mathrm{Mo}($ wt. $(\%))$ & $0.000-0.021$ \\
$\mathrm{Ti}($ wt. $(\%))$ & $0.000-0.007$ \\
$\mathrm{~N}($ wt. $(\%))$ & $0.000-0.015$ \\
$\mathrm{P}($ wt. $(\%))$ & $0.000-0.007$ \\
$\mathrm{~S}($ wt. $(\%))$ & $0.000-0.077$ \\
$\mathrm{Si}($ wt. $(\%))$ & $0.000-0.050$ \\
$\mathrm{Al}($ wt. $(\%))$ & $5-130$ \\
D $\gamma(\mu \mathrm{m})$ & $0.3-153$ \\
$\mathrm{CR}\left({ }^{\circ} \mathrm{C}\right)$ & \\
Output & $130-300$ \\
Hardness $(\mathrm{HV})$ &
\end{tabular}

The input space is decomposed by three fuzzy labels. In this paper, for comparison purposes, two types of membership functions (MFs) including the triangular (ANFIS-I) and Gaussian (ANFIS-II) were utilized to construct the suggested models. The ANFIS models were trained, from 114 collected data, by 80 data (70\%) were randomly chosen for training set, 17 (15\%) data for testing set and the other $17(15 \%)$ data for validation set. Moreover, up to 1,000 epochs were specified for training process to assure the gaining of the minimum error tolerance.

One of the most difficult tasks in ANFIS studies is to find this optimal network architecture, which is based on the determination of numbers of optimal results. The assignment of initial weights and other related parameters may also influence the performance of the ANFIS to a great extent. However, there is no well defined rule or procedure to have an optimal network architecture and parameter settings where the trial and error method still remains valid. This process is very time consuming.

In this study, the Matlab ANFIS toolbox is used for ANFIS applications. To overcome optimization difficulty, a program has been developed in Matlab, which handles the trial-and-error process automatically ${ }^{35-38}$. The program tries various functions and when the highest RMSE (root mean squared error) of the testing set, as the training of the testing set, is achieved, it was reported ${ }^{35-38}$.
The IF-THEN rules in this study were achieved as follows. Suppose that the rule base of ANFIS contains two fuzzy IF-THEN rules of Takagi and Sugeno's type:

Rule 1: IF cC is $A_{1}, c N b$ is $B_{1}, c M n$ is $C_{1}$, cMo is $D_{1}$, cTi is $E_{1}, c N$ is $F_{1}, c P$ is $G_{1}, c S$ is $H_{1}$, cSi is $I_{1}, c A l$ is $J_{1}, D \gamma$ is $\mathrm{K}_{\mathbf{1}}$ and $\mathrm{CR}$ is $\mathrm{L}_{\mathbf{1}}$

THEN $f_{1}=\mathrm{n}_{1} \mathrm{cC}+\mathrm{o}_{1} \mathrm{cNb}+\mathrm{p}_{1} \mathrm{cMn}+$ $\mathrm{q}_{1} \mathrm{cMo}+\mathrm{r}_{1} \mathrm{cTi}+\mathrm{s}_{1} \mathrm{cN}+\mathrm{t}_{1} \mathrm{cP}+\mathrm{u}_{1} \mathrm{cS}+\mathrm{v}_{1} \mathrm{cSi}+\mathrm{w}_{1} \mathrm{cAl}+\mathrm{x}_{1}$ $\mathrm{D} \gamma+\mathrm{y}_{1} \mathrm{CR}+\mathrm{zb}_{1}$.

Rule 2: IF cC is $\mathrm{A}_{2}, \mathrm{cNb}$ is $\mathrm{B}_{2}, \mathrm{cMn}$ is $\mathrm{C}_{2}$, $\mathrm{cMo}$ is $\mathrm{D}_{2}$, cTi is $E_{2}, c N$ is $F_{2}, c P$ is $G_{2}, c S$ is $H_{2}, c S i$ is $I_{2}, c A l$ is $J_{2}, D \gamma$ is $\mathrm{K}_{2}$ and $\mathrm{CR}$ is $\mathrm{L}_{2}$

THEN $f_{2}=\mathrm{n}_{2} \mathrm{cC}+\mathrm{O}_{2} \mathrm{cNb}+\mathrm{p}_{2} \mathrm{cMn}+$ $\mathrm{q}_{2} \mathrm{cMo}+\mathrm{r}_{2} \mathrm{cTi}+\mathrm{s}_{2} \mathrm{cN}+\mathrm{t}_{2} \mathrm{cP}+\mathrm{u}_{2} \mathrm{cS}+\mathrm{v}_{2} \mathrm{cSi}+\mathrm{w}_{2} \mathrm{cAl}+\mathrm{x}_{2}$ $\mathrm{D} \gamma+\mathrm{y}_{2} \mathrm{CR}+\mathrm{zb}_{2}$.

The corresponding equivalent ANFIS architecture is shown in Figure 5. The functions of each layer are described as follows:

Layer 1 - Every node $\mathrm{i}$ in this layer is a square node with a node function:

$O_{i}^{1}=\mu_{A_{i}}(c C) \quad i=1,2$

$O_{i}^{1}=\mu_{B}(c N b) \quad i=1,2$

$O_{i}^{1}=\mu_{C_{i}}(c M n) \quad i=1,2$

$O_{i}^{1}=\mu_{D_{i}}(c M o) \quad i=1,2$

$O_{i}^{1}=\mu_{E_{i}}(c T i) \quad i=1,2$

$O_{i}^{1}=\mu_{F_{i}}(c N) \quad i=1,2$

$O_{i}^{1}=\mu_{G_{i}}(c P) \quad i=1,2$

$O_{i}^{1}=\mu_{H_{i}}(c S) \quad i=1,2$

$O_{i}^{1}=\mu_{I_{i}}(c S i) \quad i=1,2$ 
$O_{i}^{1}=\mu_{J_{i}}(c A l) \quad i=1,2$

$O_{i}^{1}=\mu_{K_{i}}(D \gamma) \quad i=1,2$

$O_{i}^{1}=\mu_{L_{i}}(C R) \quad i=1,2$

where cC, cNb, cMn, cMo, cTi, cN, cP, cS, cSi, cAl, D $\gamma$ and CR are inputs to node $i$, and $A_{i}, B_{i}, C_{i}, D_{i}, E_{i}, F_{i}, G_{i}, H_{i} . I_{i}, J_{i}$, $\mathrm{K}_{\mathrm{i}}$ and $\mathrm{L}_{\mathrm{i}}$ are the linguistic label (fuzzy sets: small, large, ...) associated with this node function.
Layer 2 - Every node in this layer is a circle node labeled $\Pi$ which multiplies the incoming signals and sends the product out. For instance,

$W_{i}=\mu_{A_{i}}(c C) \times \mu_{B_{i}}(c N b) \times \mu_{C_{i}}(c M n) \times \mu_{D_{i}}(c M o) \times$

$\times \mu_{E_{i}}(c T i) \times \mu_{F_{i}}(c N) \times \mu_{G_{i}}(c P) \times \mu_{H_{i}}(c S) \times \mu_{I_{i}}(c S i) \times$

$\times \mu_{J_{i}}(c A l) \times \mu_{K_{i}}(\mathrm{D} \gamma) \times \mu_{L_{i}}(C R), \quad i=1,2$

Each node output represents the firing weight of a rule.

Layer 3 - Every node in this layer is a circle node labeled $\mathrm{N}$. The ith node calculates the ratio of the ith rule's firing weight to the sum of all rule's firing weights:

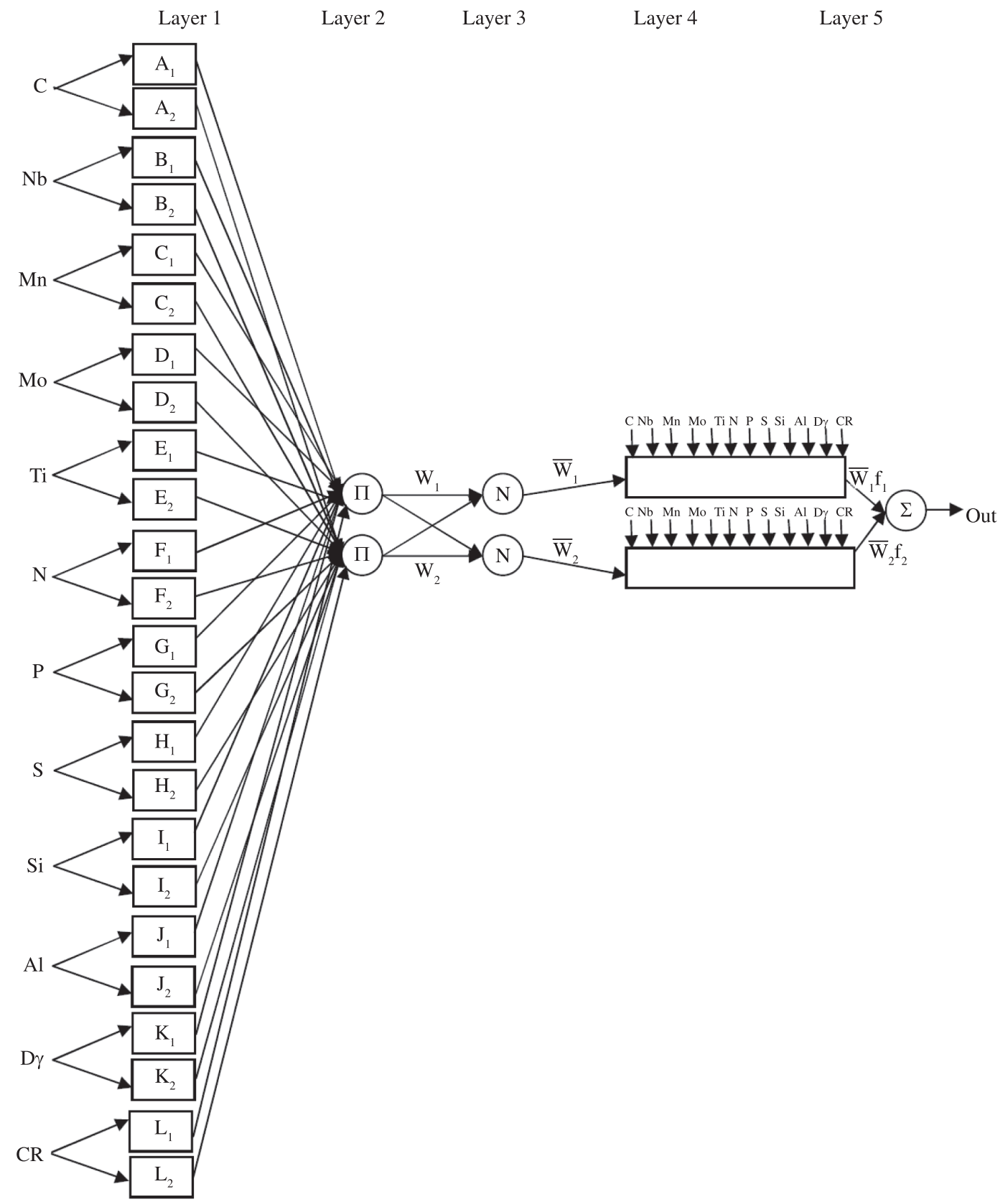

Figure 5. Schematic of ANFIS architecture utilized in this work. 


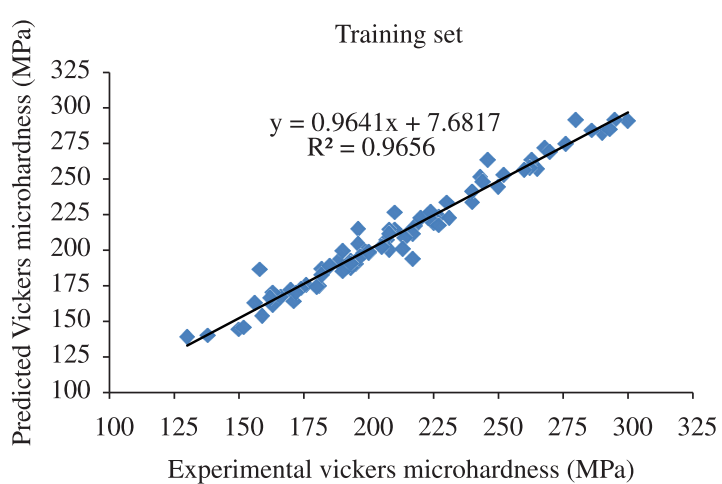

(a)

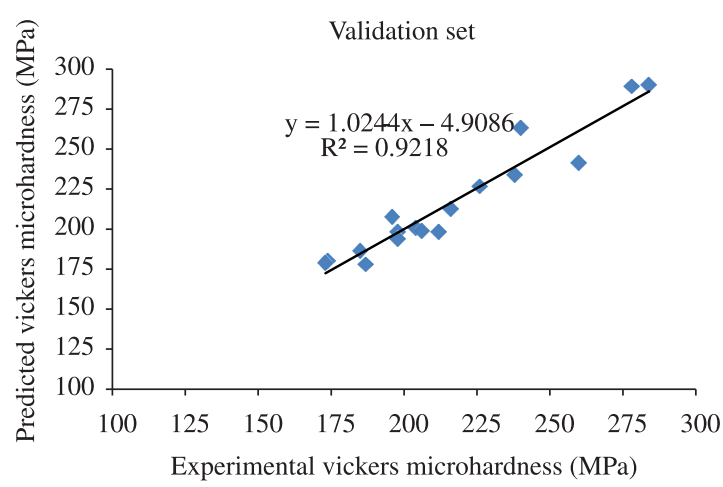

(b)

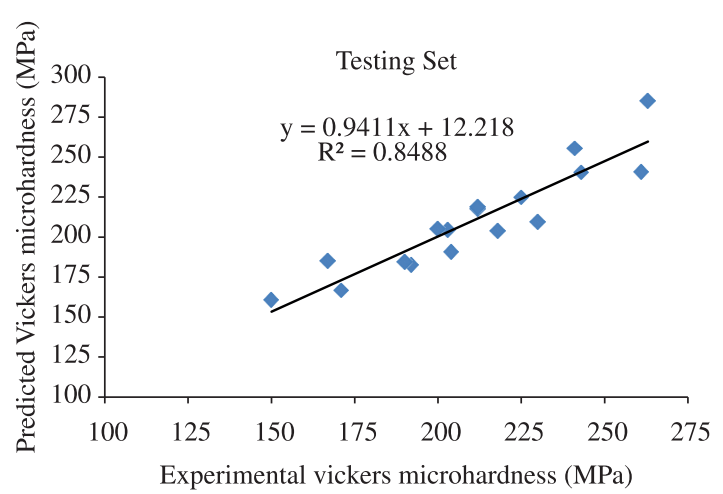

(c)

Figure 6. The correlation of the measured and predicted Vickers microhardness values in a) training, b) validation and c) testing sets for ANFIS-I model.

$W_{i}=W_{i} /\left(W_{1} / W_{2}\right), \quad i=1,2$

Layer 4 - Every node in this layer is a square node with a node function:

$O_{i}^{4}=\bar{w}_{i}\left(\begin{array}{l}n_{i} c C+o_{i} c N b+p_{i} c M n+q_{i} c M o+r_{i} c T i+s_{i} c N+ \\ +t_{i} c P+u_{i} c S+v_{i} c S i+w_{i} c A l+x_{i} D \gamma+y_{i} C R+z b_{i}\end{array}\right)$

where $\bar{W}_{i}$ is the output of layer 3 , and $\left\{n_{i}, o_{i}, p_{i}, q_{i}, r_{i}, s_{i}, t_{i}\right.$, $\left.u, v_{i}, w_{i}, x_{i}, y_{i}, z_{i}\right\}$ is the parameter set.

Layer 5 - The signal node in this layer is a circle node labeled $\mathrm{R}$ that computes the overall output as the summation of all incoming signals, i.e.,

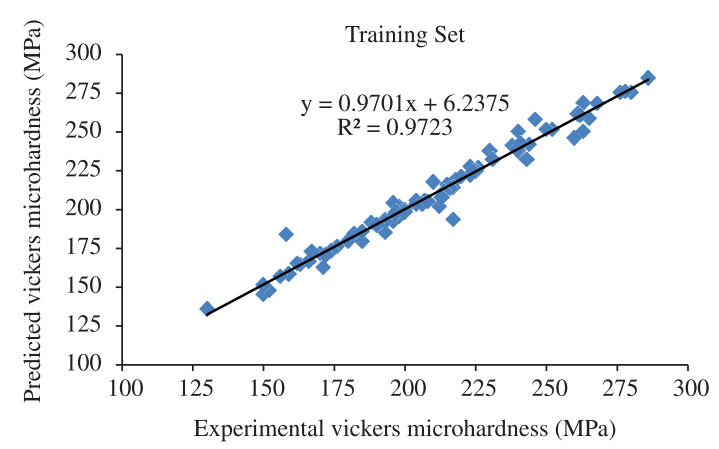

(a)

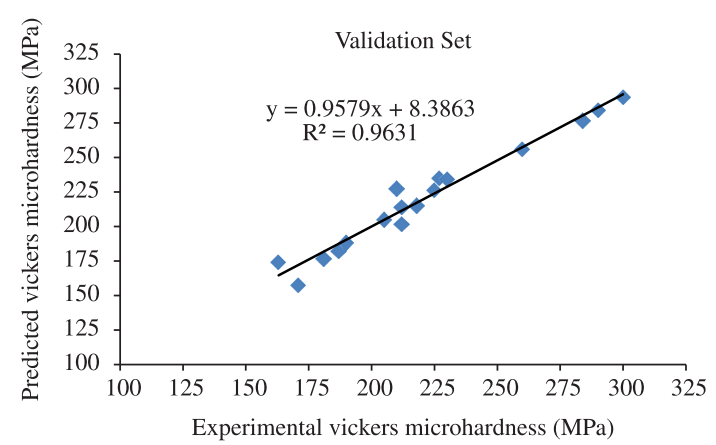

(b)

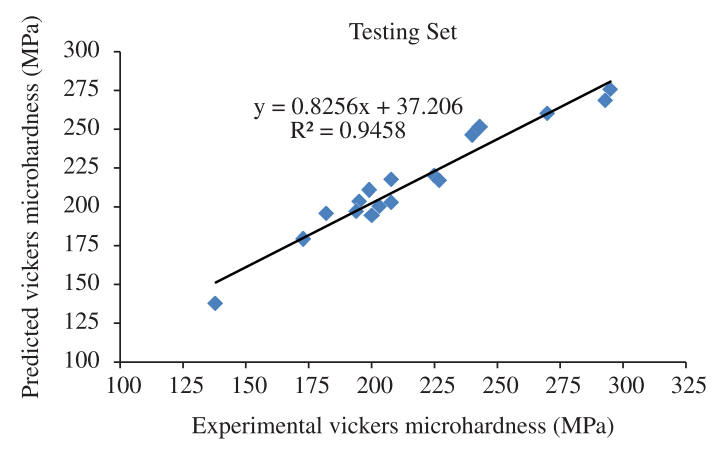

(c)

Figure 7. The correlation of the measured and predicted Vickers microhardness values in a) training, b) validation and c) testing sets for ANFIS-II model.

$O_{i}^{5}=\sum_{i} \bar{w}_{i} f_{i}=\sum_{i} w_{i} f_{i} / \sum_{i} w_{i}$

\section{Results and Discussion}

\subsection{The effects of austenitizing temperature and cooling rate}

The austenite decomposition is heavily influenced by the initial austenite grain size and cooling rate. For a given cooling rate, an increase in austenite grain size results in lower transformation start temperatures resulting in a decrease in polygonal ferrite fraction. Further, for a given austenite grain size, accelerated cooling lowers the transformation start temperature with an associated decrease 
Table 3. Testing and validation data sets for comparison of experimental results with testing and validation results predicted from ANFIS-I model.

\begin{tabular}{|c|c|c|c|c|c|c|c|c|c|c|c|c|c|c|}
\hline \multirow{2}{*}{$\begin{array}{l}\text { The set } \\
\text { name }\end{array}$} & \multicolumn{10}{|c|}{$\begin{array}{c}\text { Chemical composition } \\
\text { (wt. }(\%))\end{array}$} & \multirow{2}{*}{$\begin{array}{c}\begin{array}{c}\text { Austenite } \\
\text { Grain size }\end{array} \\
\mathbf{d} \gamma(\mu \mathrm{m})\end{array}$} & \multirow{2}{*}{$\begin{array}{c}\begin{array}{c}\text { Cooling } \\
\text { rate }\end{array} \\
\text { CR }\left({ }^{\circ} \mathbf{C}\right)\end{array}$} & \multicolumn{2}{|c|}{$\begin{array}{c}\text { Vickers } \\
\text { microhardness }\end{array}$} \\
\hline & C & $\mathrm{Nb}$ & Mn & Mo & $\mathbf{T i}$ & $\mathbf{N}$ & $\mathbf{P}$ & $\mathbf{S}$ & $\mathbf{S i}$ & Al & & & Exp. & Pred. \\
\hline \multirow[t]{17}{*}{ Validation } & 0.06 & 1.65 & 0.034 & 0.24 & 0.012 & 0.005 & 0 & 0 & 0 & 0 & 5 & 3 & 260 & 241.4 \\
\hline & 0.06 & 1.65 & 0.034 & 0.24 & 0.012 & 0.005 & 0 & 0 & 0 & 0 & 5 & 60 & 212 & 198.4 \\
\hline & 0.06 & 1.65 & 0.034 & 0.24 & 0.012 & 0.005 & 0 & 0 & 0 & 0 & 80 & 60 & 226 & 226.8 \\
\hline & 0.06 & 1.65 & 0.034 & 0.24 & 0.012 & 0.005 & 0 & 0 & 0 & 0 & 15 & 60 & 198 & 198.4 \\
\hline & 0.06 & 1.65 & 0.034 & 0.24 & 0.012 & 0.005 & 0 & 0 & 0 & 0 & 80 & 30 & 240 & 263.5 \\
\hline & 0.062 & 1.24 & 0.063 & 0.008 & 0.002 & 0.007 & 0.007 & 0.004 & 0.051 & 0.04 & 19 & 125 & 174 & 180.3 \\
\hline & 0.062 & 1.24 & 0.063 & 0.008 & 0.002 & 0.007 & 0.007 & 0.004 & 0.051 & 0.04 & 49 & 10 & 187 & 178.1 \\
\hline & 0.062 & 1.24 & 0.063 & 0.008 & 0.002 & 0.007 & 0.007 & 0.004 & 0.051 & 0.04 & 49 & 55 & 204 & 201.1 \\
\hline & 0.062 & 1.24 & 0.063 & 0.008 & 0.002 & 0.007 & 0.007 & 0.004 & 0.051 & 0.04 & 130 & 5 & 198 & 194.2 \\
\hline & 0.062 & 1.24 & 0.063 & 0.008 & 0.002 & 0.007 & 0.007 & 0.004 & 0.051 & 0.04 & 130 & 15 & 206 & 199.2 \\
\hline & 0.05 & 1.65 & 0.071 & 0.196 & 0.021 & 0 & 0.01 & 0.004 & 0.025 & 0.027 & 32 & 63 & 238 & 234.2 \\
\hline & 0.05 & 1.65 & 0.071 & 0.196 & 0.021 & 0 & 0.01 & 0.004 & 0.025 & 0.027 & 53 & 1 & 196 & 207.8 \\
\hline & 0.05 & 1.65 & 0.071 & 0.196 & 0.021 & 0 & 0.01 & 0.004 & 0.025 & 0.027 & 53 & 127 & 284 & 290.1 \\
\hline & 0.06 & 1.86 & 0 & 0.155 & 0.011 & 0.007 & 0.015 & 0.004 & 0.077 & 0.043 & 16 & 23 & 173 & 179.2 \\
\hline & 0.06 & 1.86 & 0 & 0.155 & 0.011 & 0.007 & 0.015 & 0.004 & 0.077 & 0.043 & 16 & 67 & 216 & 212.9 \\
\hline & 0.05 & 1.88 & 0.049 & 0.49 & 0 & 0.004 & 0.005 & 0.007 & 0.04 & 0.05 & 20 & 1 & 185 & 186.5 \\
\hline & 0.05 & 1.88 & 0.049 & 0.49 & 0 & 0.004 & 0.005 & 0.007 & 0.04 & 0.05 & 62 & 100 & 278 & 289.3 \\
\hline \multirow[t]{17}{*}{ Testing } & 0.06 & 1.65 & 0.034 & 0.24 & 0.012 & 0.005 & 0 & 0 & 0 & 0 & 42 & 60 & 225 & 225 \\
\hline & 0.06 & 1.65 & 0.034 & 0.24 & 0.012 & 0.005 & 0 & 0 & 0 & 0 & 42 & 100 & 203 & 204.7 \\
\hline & 0.06 & 1.65 & 0.034 & 0.24 & 0.012 & 0.005 & 0 & 0 & 0 & 0 & 80 & 100 & 204 & 190.7 \\
\hline & 0.06 & 1.65 & 0.034 & 0.24 & 0.012 & 0.005 & 0 & 0 & 0 & 0 & 24 & 30 & 243 & 240.5 \\
\hline & 0.06 & 1.65 & 0.034 & 0.24 & 0.012 & 0.005 & 0 & 0 & 0 & 0 & 80 & 10 & 263 & 285.2 \\
\hline & 0.062 & 1.24 & 0.063 & 0.008 & 0.002 & 0.007 & 0.007 & 0.004 & 0.051 & 0.04 & 49 & 18 & 192 & 182.9 \\
\hline & 0.062 & 1.24 & 0.063 & 0.008 & 0.002 & 0.007 & 0.007 & 0.004 & 0.051 & 0.04 & 49 & 110 & 212 & 217.9 \\
\hline & 0.062 & 1.24 & 0.063 & 0.008 & 0.002 & 0.007 & 0.007 & 0.004 & 0.051 & 0.04 & 49 & 192 & 218 & 204.3 \\
\hline & 0.05 & 1.65 & 0.071 & 0.196 & 0.021 & 0 & 0.01 & 0.004 & 0.025 & 0.027 & 14 & 172 & 230 & 209.8 \\
\hline & 0.05 & 1.65 & 0.071 & 0.196 & 0.021 & 0 & 0.01 & 0.004 & 0.025 & 0.027 & 32 & 1 & 190 & 184.6 \\
\hline & 0.05 & 1.65 & 0.071 & 0.196 & 0.021 & 0 & 0.01 & 0.004 & 0.025 & 0.027 & 32 & 172 & 261 & 240.7 \\
\hline & 0.05 & 1.65 & 0.071 & 0.196 & 0.021 & 0 & 0.01 & 0.004 & 0.025 & 0.027 & 53 & 12 & 212 & 218.9 \\
\hline & 0.06 & 1.86 & 0 & 0.155 & 0.011 & 0.007 & 0.015 & 0.004 & 0.077 & 0.043 & 16 & 1 & 150 & 160.6 \\
\hline & 0.06 & 1.86 & 0 & 0.155 & 0.011 & 0.007 & 0.015 & 0.004 & 0.077 & 0.043 & 24 & 5 & 171 & 166.8 \\
\hline & 0.05 & 1.88 & 0.049 & 0.49 & 0 & 0.004 & 0.005 & 0.007 & 0.04 & 0.05 & 8 & 1 & 167 & 185.3 \\
\hline & 0.05 & 1.88 & 0.049 & 0.49 & 0 & 0.004 & 0.005 & 0.007 & 0.04 & 0.05 & 20 & 100 & 241 & 255.6 \\
\hline & 0.05 & 1.88 & 0.049 & 0.49 & 0 & 0.004 & 0.005 & 0.007 & 0.04 & 0.05 & 62 & 5 & 200 & 205.1 \\
\hline
\end{tabular}

in the polygonal ferrite fraction in addition to refining the resulting ferrite grains. Accelerated cooling in combination with smaller austenite grain sizes further refines the ferrite grains. The effect of processing variables indicates that the hardness increases with austenite grain size and cooling rate as a result of the decrease in transformation start temperature where low temperature transformation products are formed, i.e. bainite and martensite, which are harder phases.

Predicting the microstructural evolution under continuous cooling conditions as found on the welding is a challenging task since in addition to cooling conditions, the austenite decomposition is affected by chemistry, austenite grain size and retained strain. There is a clear shift of the transformation kinetics to lower transformation temperatures with an increase in the initial austenite grain size. A larger initial austenite grain size provides less boundary surface area per unit volume, thus reducing the number of available nucleation sites for ferrite and as a result transformation occurs at lower temperatures. In addition, the carbon diffusion distance is greater for a larger initial austenite grain size requiring additional time for diffusion, thereby lowering the transformation temperature. The shift to lower transformation start temperatures for an increase in the initial austenite grain size, is associated with the delay of transformation start for larger austenite grains since, comparatively they provide fewer nucleation sites. Similar trends were observed for transformation finish temperatures. The increase in cooling rate and/or initial austenite grain size gave rise to a significant increase in the hardness of the steel. For example, for HSLA $90^{[27]}$ an increase in the cooling rate from 1 to $179{ }^{\circ} \mathrm{C} / \mathrm{s}$ increased the hardness by $90 \mathrm{HV}$ for an austenite grain size of $53 \mu \mathrm{m}$ and for an increase in the 
Table 4. Testing and validation data sets for comparison of experimental results with testing and validation results predicted from ANFIS-II model.

\begin{tabular}{|c|c|c|c|c|c|c|c|c|c|c|c|c|c|c|}
\hline \multirow{2}{*}{$\begin{array}{l}\text { The set } \\
\text { name }\end{array}$} & \multicolumn{10}{|c|}{$\begin{array}{c}\text { Chemical composition } \\
\text { (wt. }(\%))\end{array}$} & \multirow{2}{*}{$\begin{array}{c}\begin{array}{c}\text { Austenite } \\
\text { Grain size }\end{array} \\
\mathrm{d} \gamma(\mu \mathrm{m})\end{array}$} & \multirow{2}{*}{$\begin{array}{c}\begin{array}{c}\text { Cooling } \\
\text { rate }\end{array} \\
\text { CR }\left({ }^{\circ} \mathrm{C}\right)\end{array}$} & \multicolumn{2}{|c|}{$\begin{array}{c}\text { Vickers } \\
\text { Microhardness }\end{array}$} \\
\hline & C & Nb & Mn & Mo & $\mathbf{T i}$ & $\mathbf{N}$ & $\mathbf{P}$ & $\mathbf{S}$ & $\mathbf{S i}$ & Al & & & Exp. & Pred. \\
\hline \multirow[t]{17}{*}{ Validation } & 0.06 & 1.65 & 0.034 & 0.24 & 0.012 & 0.005 & 0 & 0 & 0 & 0 & 42 & 3 & 300 & 293.6 \\
\hline & 0.06 & 1.65 & 0.034 & 0.24 & 0.012 & 0.005 & 0 & 0 & 0 & 0 & 42 & 10 & 290 & 284.3 \\
\hline & 0.06 & 1.65 & 0.034 & 0.24 & 0.012 & 0.005 & 0 & 0 & 0 & 0 & 42 & 60 & 225 & 226.4 \\
\hline & 0.06 & 1.65 & 0.034 & 0.24 & 0.012 & 0.005 & 0 & 0 & 0 & 0 & 80 & 60 & 210 & 227.4 \\
\hline & 0.062 & 1.24 & 0.063 & 0.008 & 0.002 & 0.007 & 0.007 & 0.004 & 0.051 & 0.04 & 49 & 5 & 181 & 176.7 \\
\hline & 0.062 & 1.24 & 0.063 & 0.008 & 0.002 & 0.007 & 0.007 & 0.004 & 0.051 & 0.04 & 49 & 10 & 187 & 182.3 \\
\hline & 0.062 & 1.24 & 0.063 & 0.008 & 0.002 & 0.007 & 0.007 & 0.004 & 0.051 & 0.04 & 49 & 110 & 212 & 201.8 \\
\hline & 0.062 & 1.24 & 0.063 & 0.008 & 0.002 & 0.007 & 0.007 & 0.004 & 0.051 & 0.04 & 49 & 192 & 218 & 215.1 \\
\hline & 0.062 & 1.24 & 0.063 & 0.008 & 0.002 & 0.007 & 0.007 & 0.004 & 0.051 & 0.04 & 130 & 198 & 227 & 235.1 \\
\hline & 0.05 & 1.65 & 0.071 & 0.196 & 0.021 & 0 & 0.01 & 0.004 & 0.025 & 0.027 & 14 & 1 & 163 & 174.3 \\
\hline & 0.05 & 1.65 & 0.071 & 0.196 & 0.021 & 0 & 0.01 & 0.004 & 0.025 & 0.027 & 14 & 172 & 230 & 234.2 \\
\hline & 0.05 & 1.65 & 0.071 & 0.196 & 0.021 & 0 & 0.01 & 0.004 & 0.025 & 0.027 & 32 & 1 & 190 & 188.3 \\
\hline & 0.05 & 1.65 & 0.071 & 0.196 & 0.021 & 0 & 0.01 & 0.004 & 0.025 & 0.027 & 53 & 12 & 212 & 214.2 \\
\hline & 0.05 & 1.65 & 0.071 & 0.196 & 0.021 & 0 & 0.01 & 0.004 & 0.025 & 0.027 & 53 & 127 & 284 & 276.7 \\
\hline & 0.06 & 1.86 & 0 & 0.155 & 0.011 & 0.007 & 0.015 & 0.004 & 0.077 & 0.043 & 16 & 5 & 171 & 157.5 \\
\hline & 0.06 & 1.86 & 0 & 0.155 & 0.011 & 0.007 & 0.015 & 0.004 & 0.077 & 0.043 & 24 & 48 & 205 & 205.1 \\
\hline & 0.06 & 1.86 & 0 & 0.155 & 0.011 & 0.007 & 0.015 & 0.004 & 0.077 & 0.043 & 24 & 157 & 260 & 255.9 \\
\hline \multirow[t]{17}{*}{ Testing } & 0.06 & 1.65 & 0.034 & 0.24 & 0.012 & 0.005 & 0 & 0 & 0 & 0 & 42 & 100 & 203 & 200.6 \\
\hline & 0.06 & 1.65 & 0.034 & 0.24 & 0.012 & 0.005 & 0 & 0 & 0 & 0 & 80 & 3 & 295 & 275.7 \\
\hline & 0.06 & 1.65 & 0.034 & 0.24 & 0.012 & 0.005 & 0 & 0 & 0 & 0 & 80 & 10 & 293 & 268.8 \\
\hline & 0.06 & 1.65 & 0.034 & 0.24 & 0.012 & 0.005 & 0 & 0 & 0 & 0 & 5 & 3 & 240 & 246.4 \\
\hline & 0.06 & 1.65 & 0.034 & 0.24 & 0.012 & 0.005 & 0 & 0 & 0 & 0 & 5 & 30 & 208 & 218 \\
\hline & 0.06 & 1.65 & 0.034 & 0.24 & 0.012 & 0.005 & 0 & 0 & 0 & 0 & 80 & 100 & 195 & 203.8 \\
\hline & 0.062 & 1.24 & 0.063 & 0.008 & 0.002 & 0.007 & 0.007 & 0.004 & 0.051 & 0.04 & 19 & 2.5 & 138 & 137.8 \\
\hline & 0.05 & 1.65 & 0.071 & 0.196 & 0.021 & 0 & 0.01 & 0.004 & 0.025 & 0.027 & 14 & 20 & 182 & 195.7 \\
\hline & 0.05 & 1.65 & 0.071 & 0.196 & 0.021 & 0 & 0.01 & 0.004 & 0.025 & 0.027 & 32 & 6.7 & 194 & 197.2 \\
\hline & 0.05 & 1.65 & 0.071 & 0.196 & 0.021 & 0 & 0.01 & 0.004 & 0.025 & 0.027 & 32 & 17 & 199 & 211 \\
\hline & 0.05 & 1.65 & 0.071 & 0.196 & 0.021 & 0 & 0.01 & 0.004 & 0.025 & 0.027 & 32 & 120 & 243 & 251.7 \\
\hline & 0.05 & 1.65 & 0.071 & 0.196 & 0.021 & 0 & 0.01 & 0.004 & 0.025 & 0.027 & 53 & 5 & 208 & 202.9 \\
\hline & 0.06 & 1.86 & 0 & 0.155 & 0.011 & 0.007 & 0.015 & 0.004 & 0.077 & 0.043 & 16 & 23 & 173 & 179.6 \\
\hline & 0.06 & 1.86 & 0 & 0.155 & 0.011 & 0.007 & 0.015 & 0.004 & 0.077 & 0.043 & 32 & 155 & 270 & 260.2 \\
\hline & 0.05 & 1.88 & 0.049 & 0.49 & 0 & 0.004 & 0.005 & 0.007 & 0.04 & 0.05 & 8 & 15 & 200 & 194.7 \\
\hline & 0.05 & 1.88 & 0.049 & 0.49 & 0 & 0.004 & 0.005 & 0.007 & 0.04 & 0.05 & 8 & 40 & 225 & 220.4 \\
\hline & 0.05 & 1.88 & 0.049 & 0.49 & 0 & 0.004 & 0.005 & 0.007 & 0.04 & 0.05 & 62 & 15 & 227 & 217.1 \\
\hline
\end{tabular}

austenite grain size from 14 to $53 \mu \mathrm{m}$, the hardness increased by $58 \mathrm{HV}$ for a cooling rate of $127^{\circ} \mathrm{C} / \mathrm{s}$.

The observed increase in hardness obtained by increasing the cooling rate is related to a decrease in the transformation temperatures for which non-polygonal products, i.e. harder phases are formed. In addition, decreasing the austenite grain size also results in an increase in hardness; this is due to the refinement of ferrite grains with a decrease in the austenite grain size.

\subsection{ANFIS modeling}

In this study, the error arose during the training, Validation and testing in ANFIS-I and ANFIS-II models can be expressed as absolute fraction of variance $\left(\mathrm{R}^{2}\right)$ which is calculated by Equation 2:

$$
R^{2}=1-\left(\frac{\sum_{i}\left(t_{i}-o_{i}\right)^{2}}{\sum_{i}\left(o_{i}\right)^{2}}\right)
$$

where $t$ is the target value and o is the output value.

All of the results obtained from experimental studies and predicted by using the training, testing and validation results of ANFIS-I and ANFIS-II models are given in Figures 6a-c and $7 \mathrm{a}-\mathrm{c}$, respectively. The linear least square fit line, its equation and $\mathrm{R}^{2}$ values were shown in these figures for the training, testing and validation data. Also, inputs values and experimental results with testing and validation results obtained from ANFIS-I and ANFIS-II models were given in Tables 3 and 4, respectively. As it is visible in Figures 6 and 7 , the values obtained from the training, testing and validation sets in ANFIS-I and ANFIS-II models are very 
close to the experimental results. The results of testing and validation phases in Figures 6 and 7 show that the ANFIS-I and ANFIS-II models are capable of generalizing between input and output variables with reasonably good predictions.

The performance of the ANFIS-I and ANFIS-II models is shown in Figures 6 and 7. The best value of $\mathrm{R}^{2}$ is $96.56 \%$ for training set in the ANFIS-I model. The minimum values of $\mathrm{R}^{2}$ are $97.23 \%$ for training set in the ANFIS-II model. All of $\mathrm{R}^{2}$ values show that the proposed ANFIS-I and ANFIS-II models are suitable and can predict Vickers microhardness of microalloyed steels values very close to the experimental values.

\section{Conclusion}

1. The effect of processing variables shows that the hardness of steels increases with the increase of austenite grain size and cooling rate attributed to the

\section{References}

1. DeArdo AJ. Modern thermomechanical processing of microalloyed steel: A physical metallurgy perspective. In: Proceedings of Microalloying '95 Conference; 1995; Pittsburgh. ISS; 1995. p. 15-33.

2. Ouchi C. Development of Steel Plates by Intensive Use of TMCP and. Direct Quenching Processes. ISIJ International. 2001;14:542-553. http://dx.doi.org/10.2355/ isijinternational.41.542

3. Kwon $\mathrm{O}$ and DeArdo AJ. Interactions between recrystallization and precipitation in hot-deformed microalloyed steels. Acta Metallurgica et Materialia. 1991; 39(4):529-38. http://dx.doi. org/10.1016/0956-7151(91)90121-G

4. Volb-ath LGE, Hackl R, Schmitt-Thomas KG and Daub D. Influence of TM-Rolling Parameters on Properties of Microalloyed Cold Rolled Steels. In: Microalloying '88; 1988; Metals Park. ASM 1988. p. 353-358.

5. Honeycombe R and Bhadeshia H. Steels: Microstructure and Properties. London: Edward Arnold; 1995.

6. Tamura I, Ouchi C, Tanaka T and Sekine H. Thermomechanical Processing of High Strength Low Alloy Steels. London: Butterworths; 1998. p. 21.

7. Okaguchi $\mathrm{S}$, Hasimoto $\mathrm{T}$ and Ohtani H. Effect of $\mathrm{Nb}, \mathrm{V}$ and Ti on Transformation Behavior of HSLA. Steel in Accelerated Cooling. In: THERMEC'88; 1988. IS1J, 1988. vol. 1, p. 330.

8. Oberhauser F, Listhuber F and Wallener F. Microalloying Steels for Light, Cold-Formed Sections. In: Mircoalloying'75; 1975; New York. Union Carbide Corporation; 1977. p. 665.

9. Collins L and Liu W. Phase Transformation During the Thermal/Mechanical Processing of Steel. The Metallurgical Society of CIM; 1995. p. 419.

10. Pandi R. Modelling of Austenite to Ferrite Transformation Behaviour in Low Carbon Steels During Run-out Table Cooling. [Dissertation]. Vancouver: The University of British Columbia; 1998.

11. Militzer M, Pandi R and Hawbolt B. Ferrite nucleation and growth during continuous cooling. Metallurgical and Materials Transactions A. 1996; 27(6):1547-1556. http:// dx.doi.org/10.1007/BF02649814

12. Militzer M, Hawbolt $B$ and Meadowcroft $R$. Microstructural model for hot strip rolling of highstrength low-alloy steels. Metallurgical and Materials Transactions. 2000; 31(4):1247-1259. http://dx.doi. org/10.1007/s11661-000-0120-4 increase in non-polygonal structures which show a higher hardness. This effect can be rationalized with transformation temperature, e.g. a decreasing transformation start temperature leads to higher hardness values; and

2. The ANFIS approach appears to be a very powerful tool in materials engineering. The results presented show that the prediction of the microhardness properties of the considered steel is in a good agreement with the experimental data. The ANFIS was trained, Tested and validated on the data obtained from the literature. The accuracy of values evaluated by the ANFIS model is much higher than that obtained from calculations using the classical, experimental models. This means that the well-trained network under laboratory conditions is able to predict the correct values of the output parameters of the industrial process.

13. Militzer M, Hawbolt B and Meadowcroft R. Phase Transformation During the Thermal/Mechanical Processing of Steel. The Metallurgical Society of CIM; 1995. p. 445.

14. Porter DA and Easterling KE. Phase Transformations in Metals and Alloys. 2nd ed. London: Chapman and Hall; 1992.

15. Nakata N and Militzer M. Microstructure Evolution of a Stateof-the-Art Ti-Nb HSLA Steel. In: Mechanical Working and Steel Processing Conference Proceedings; 2000; Warrendale. ISS; 2000. vol. 38, p. 813.

16. Hawbolt B, Chau B and Brimacombe K. Mathematical Modelling of Hot Rolling of Steel. Canada: The Metallurgical Society of CIM; 1990. p. 424.

17. Pandi R, Militzer M, Hawbolt B and Meadowcroft R. Effect of Cooling and Deformation on the Austenite Decomposition Kinetics. In: Proceedings of 37th Mechanical Working and Steel Processing Conference; 1995; Warrendale. ISS; 1995. p. 635

18. Nazari A and Milani AA. Modeling ductile to brittle transition temperature of functionally graded steels by artificial neural networks. Computational Materials Science. 2011; 50:2028-2037. http://dx.doi.org/10.1016/j. commatsci.2011.02.003

19. Nazari A and Milani AA. Modeling ductile to brittle transition temperature of functionally graded steels by fuzzy logic. Journal of Materials Science. 2011; 46(18):6007-6017. http:// dx.doi.org/10.1007/s10853-011-5563-z

20. Nazari A and Riahi S. Computer-aided prediction of physical and mechanical properties of high strength cementitious composite containing $\mathrm{Cr}_{2} \mathrm{O}_{3}$ nanoparticles. Nano. 2010; 5(5):301-318. http://dx.doi.org/10.1142/S1793292010002219

21. Nazari A and Riahi S. Prediction split tensile strength and water permeability of high strength concrete containing $\mathrm{TiO}_{2}$ nanoparticles by artificial neural network and genetic programming. Composites Part B: Engineering. 2011; 42:473-488. http://dx.doi.org/10.1016/j. compositesb.2010.12.004

22. Nazari A and Riahi S. Computer-aided design of the effects of $\mathrm{Fe}_{2} \mathrm{O}_{3}$ nanoparticles on split tensile strength and water permeability of high strength concrete. Materials and Design. 2011; 32:3966-3979. http://dx.doi.org/10.1016/j. matdes.2011.01.064

23. Nazari A and Didehvar N. Modeling impact resistance of aluminum-epoxy laminated composites. ANFIS. 2011; 42:1912-1919.

24. Jang JSR. ANFIS: adaptive-network-based fuzzy inference system. IEEE Transactions on Systems, Man 
and Cybernetics. 1993; 23(3):665-85. http://dx.doi. org/10.1109/21.256541

25. Saridemir M. Predicting the compressive strength of mortars containing metakaolin by artificial neural networks and fuzzy logic. Advances in Engineering Software. 2009; 40(9):920-7. http://dx.doi.org/10.1016/j.advengsoft.2008.12.008

26. Ramezanianpour AA, Sobhani M and Sobhani J. Application of network based neuro-fuzzy system for prediction of the strength of high strength concrete. Amirkabir Journal of Science and Technology. 2004; 5(59-C):78-93.

27. Ramezanianpour AA, Sobhani J and Sobhani M. Application of an adaptive neurofuzzy system in the prediction of HPC compressive strength. In: Proceedings of the 4th international conference on engineering computational technology; 2004; Lisbon. Lisbon: Civil-Comp Press; 2004. p. 138.

28. Topcu IB and Sarıdemir M. Prediction of mechanical properties of recycled aggregate concretes containing silica fume using artificial neural networks and fuzzy logic. Computational Materials Science. 2008; 42(1):74-82. http:// dx.doi.org/10.1016/j.commatsci.2007.06.011

29. Jang JSR and Sun CT. Nuro-fuzzy modeling and control. Proceedings of IEEE. 1995; 83(3). http://dx.doi. org/10.1109/5.364486

30. Tafteh R. Austenite decomposition in an X80 linepipe steel. [Thesis]. The University of British Columbia; 2011.

31. Lottey KK. Austenite decomposition of a HSLA-Nb, Ti steel and an A1-TRIP steel during continuous cooling. [Thesis]. The University of British Columbia; 2002.
32. Olasolo M, Uranga P, Rodriguez-Ibabe JM and López B. Effect of austenite microstructure and cooling rate on transformation characteristics in a low carbon $\mathrm{Nb}-\mathrm{V}$ microalloyed steel. Materials Science and Engineering A. 2011; 528:2559-2569. http://dx.doi.org/10.1016/j.msea.2010.11.078

33. Petkov P. Austenite decomposition of low carbon high strength steels during continuous cooling. [Thesis]. The University of British Columbia; 2004.

34. Sarkar S. Microstructural evolution model for hot strip rolling of a Nb-Mo complex-phase steel. [Thesis]. The University of British Columbia; 2008.

35. Guzelbey IH, Cevik A and Erklig A. Prediction of web crippling strength of cold-formed steel sheetings using neural Networks. Journal of Constructional Steel Research. 2006; 62:962-973. http://dx.doi.org/10.1016/j.jcsr.2006.01.008

36. Guzelbey IH, Cevik A and Gögüs MT. Prediction of rotation capacity of wide flange beams using neural Networks. Journal of Constructional Steel Research. 2006; 62:950-961. http:// dx.doi.org/10.1016/j.jcsr.2006.01.003

37. Cevik A and Guzelbey IH. Neural network modeling of strength enhancement for CFRP confined concrete cylinders. Building and Environment. 2008; 43:751-763. http://dx.doi. org/10.1016/j.buildenv.2007.01.036

38. Cevik A and Guzelbey IH. A Soft computing based approach for the prediction of ultimate strength of metal plates in compression. Engineering Structures. 2007; 29(3):383-394. http://dx.doi.org/10.1016/j.engstruct.2006.05.005 